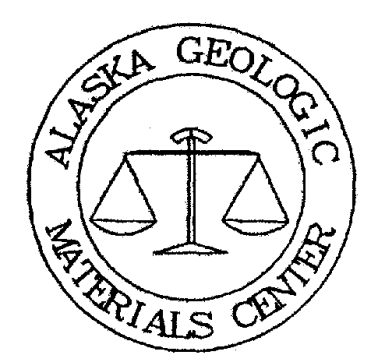

Sr 87/86 isotope analyses of the following North Slope well materials:

Exxon Corporation Alaska State F No.1, washed cuttings $\left(13,980^{\prime}\right.$ - 13,990');

ARCO Alaska Inc. West Mikkelsen State No.1, core chips $(15,569 ')$;

Exxon Corporation Canning River Unit Blk A No.1, washed cuttings $\left(8,350^{\prime}-8,360^{\prime}, 8,550^{\prime}-8,560^{\prime}\right)$ and core chips $\left(8,866^{\prime}-8,867^{\prime}, 8,871^{\prime}-8,872^{\prime}\right)$;

Mobil Oil Corporation Mikkelsen Bay State 13-09-19, core chips $\left(16,543^{\prime}, 16,578^{\prime}\right.$, and $\left.16,580^{\prime}\right)$; and

Exxon Corporation Point Thomson Unit No.2, washed cuttings $\left(13,720^{\prime}-13,730^{\prime}\right)$.<smiles>C1=CC=C2C=CC=CC=c3ccc(c(c3)C=C1)=C2</smiles>

Received 18 February, 1992 
December 31, 1991

\section{Dr. John Reeder}

State of Alaska

Div. of Geologic and Geophysical Surveys

Geologic Materials Center

P. O. Box 772116

Eagle River, Alaska 99577

Dear John,

Enclosed are $\mathrm{Sr} 87 / 86$ isotope analyses for a subset of the various wells which Gordon Fielder and I sampled on our visit to the GMC on September 9-11, 1991. The following information applies.

EXXON Alaska State F-1

API 5008920019

Cuttings: $13,980-90 \quad .709953 \pm 10$

ARCO West Mikkelsen 1

API 5002920278

$\begin{array}{ll}\text { Core chip: } & 15,569 \quad .710696 \pm 8 \\ & 710586 \pm 9\end{array}$

EXXON Canning River 1-A

API 50179200050000

Cuttings: $8,350-60 \quad .708734 \pm 10$

$8,550-60 \quad .709004 \pm 10$

$.709187 \pm 8$

Core chips: $8,866-67 \quad .709362 \pm 8$

8,871-72 $.708642 \pm 10$

$.708687 \pm 11$

MOBIL Mikkelsen 13-9-19

API 5002920055000

Core chips: $16,543 \quad .711606 \pm 10$

$.709127 \pm 8$

$16,578 \quad .708822 \pm 11$

$16,580 \quad .708357 \pm 11$

$.708198 \pm 10$ 


\section{EXXON PTU 2}

\section{API 5008920006}

Cuttings: $13,720-30 \quad .708987 \pm 10$

The analyses were performed on a Vacuum Generators "Sector" mass spectrometer with seven adjustable Faraday collectors equipped with $10^{11} \mathrm{ohm}$ resistors and Solartron digital voltmeters. The samples were analyzed using a triple collector peak hopping or "multi-dynamic" procedure that eliminates gain differences between collectors. The carbonate phases were dissolved preferentially using dilurte acids. Samples that were identified as "dolomite" were leached with $1 \mathrm{~N} \mathrm{HCl}$ to partially dissolve dolomite. Samples that were identified as "limestone" were leached with iN acetic acid to preferentially dissolve calcite. In each case we were attempting to leach only the carbonate fraction and not include silicate components so we used a weak acid. The attached table provides the isotopic composition. The precisions specified are two standard error of the mean expressed as uncertainties in the least significant figure (sixth decimal place).

I apologize for not returning these analyses to you earlier, but I have been waiting on the residual sample to be returned to me. In the interim, I am sending the geochemical data without the residue. As soon as I receive the residual material, I will forward it to you.

Once again thank-you for all your help. Please do not hesitate to call with any questions.

Sincerely,

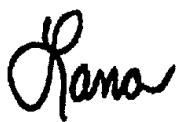

Lana Ann Czerniakowski

cc K. A. McGill

G. W. Fielder 